82

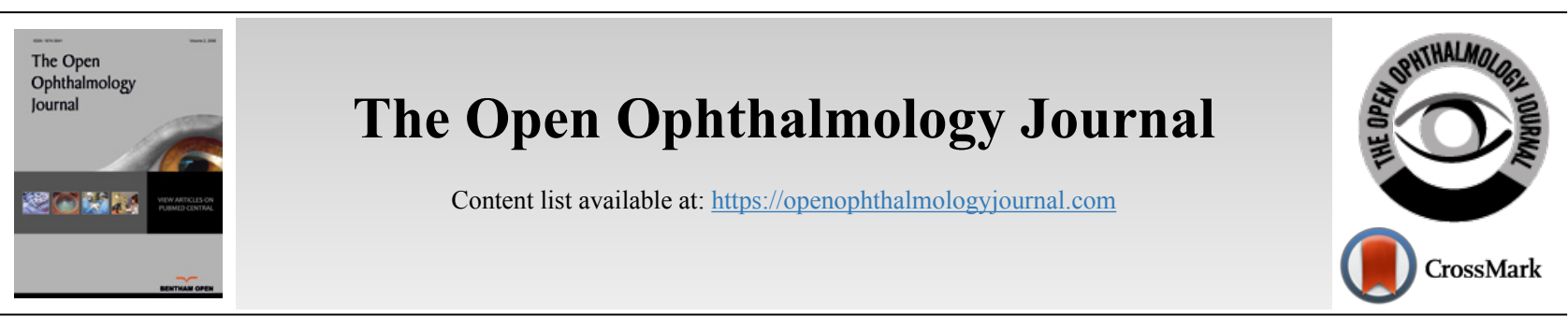

CLINICAL TRIAL STUDY

\title{
Comparing Adjuvant Beta Radiation, Mitomycin C, and Conjunctival Autograft in Primary Pterygium Treatment, a Three-year Follow-up Study
}

\author{
Khalil M. Al-Salem ${ }^{1, *}$, Ahmad T.S. Saif ${ }^{2}$ and Passant S. Saif ${ }^{3}$ \\ ${ }^{1}$ Department of Ophthalmology and Visual Sciences, Mutah University, Al-Karak, Jordan \\ ${ }^{2}$ Department of Ophthalmology, Fayoum University, Fayoum University Hospital, Fayoum, Egypt \\ ${ }^{3}$ Department of Ophthalmology, Misr University for Science and Technology, Giza, Egypt
}

\begin{abstract}
:
Purpose:

To compare the recurrence rate of primary pterygium surgery after the adjuvant use of Beta radiation, Mitomycin C, and conjunctival autograft.

Methods:

180 eyes of 180 patients were included in the study. All cases had primary pterygium excision following the use of adjuvant therapy of Beta radiation or Mitomycin C $(0.02 \%$ for 5 minutes $)$ or conjunctival autograft. The study was conducted at Fayoum University Hospital, Fayoum, Egypt, and Misr University Hospital. The patients were randomly divided into three groups, with each group comprising 60 patients. Group (A) included patients treated with Beta radiation following Pterygium excision, group (B) patients had primary pterygium excision with the application of $0.02 \%$ Mitomycin $\mathrm{C}$ for 5 minutes, and group (C) patients had conjunctival autograft to cover the bare area after pterygium excision. Patients were followed up for three years postoperatively.

Results:

group A had the highest recurrence rate (33.3\%) followed by group B (13.3\%), and finally group C presented a recurrence rate of $6.7 \%$. Group B showed the highest rate of intra-ocular postoperative complications, while no intra-ocular complications were recorded in group C. Common complications in groups A and B were scleral melting, keratitis, and Dellen formation.

Conclusion:

Using conjunctival autograft after primary pterygium excision gives the best results regarding the rate of recurrence and postoperative complications. Meanwhile, B-radiation or Mitomycin C did not prove to be as good.
\end{abstract}

Keywords: Pterygium surgery, Adjuvant use of Mitomycin C, Beta radiation, Conjunctival Autograph, Conjunctival flap, Recurrence rate Pterygium surgery complications.

\section{INTRODUCTION}

The recurrence of pterygium after surgical excision remains a problem. Various intraoperative and postoperative methods have been tried to lower the recurrence. Examples are radiotherapy, the use of antineoplastic drugs, and the use of conjunctival autograft or flap [1 - 4].

Recently, the use of postoperative cyclosporin A and injection of anti-vascular endothelial growth factors have been reported with variable success rates [5 - 7].

\footnotetext{
* Address correspondence to this author at the Department of Ophthalmology and visual sciences, Mutah University, Al-Karak, Box: 830910, Amman, Jordan; Tel: 00962797262600; E-mail: khalil_alsalem@hotmail.com
}

Commonly, pterygium recurrence occurs during the first six months after surgery. Several factors may increase recurrences, such as type of pterygium, age of patient, environment, and surgical technique [8 - 10].

Herein, we share our experience of the treatment of pterygium using either one of the three methods; simple excision followed by Beta radiation, simple removal with Mitomycin $\mathrm{C}$ application, and simple removal combined with conjunctival autograft. The three methods were compared in terms of recurrence and postoperative complications. 


\section{METHODS}

This prospective controlled study was conducted following the Helsinki Declaration and was approved by the Institutional Review Board and Research Ethics Committee of Fayoum University (2139/10/2016).

The study was conducted in two hospitals, Fayoum University Hospital and Misr University hospital, Egypt. A total of 180 patients were enrolled in the study.

Of the 180 cases, 120 were recruited at Fayoum University Hospital by Seif A. Of these, 60 cases underwent primary pterygium excision followed by conjunctival grafting. The other group, which consisted of 60 cases, underwent primary pterygium excision followed by adjuvant use of B-radiation. Meanwhile, the group that underwent primary pterygium excision followed by mitomycin $\mathrm{C}$ was recruited at Misr University Hospital by Seif P. The study was conducted between October 2016 and October 2019. All cases were done in the first six months to ensure an approximate three-year follow-up for every patient. Data collection was performed by Seif $A$ and Seif $P$.

All patients underwent a preoperative assessment of corrected visual acuity, slit-lamp anterior segment examination, intraocular pressure measurement, and fundus examination.

The patients' age range was 40 to 60 years. Both genders were enrolled in the study. All patients had primary pterygium. All types of pterygium were enrolled in the study irrespective of pterygium's base width, vascularity, and thickness.

Patients with an inflamed pterygium were given fluorometholone $(0.01 \%)$ three times for a month before pterygium excision.

Patients with recurrent pterygium, previous intraocular surgery, autoimmune diseases, history of cataract, history of glaucoma, or any vision affecting illness were excluded from the study.

The postoperative follow-up period was three years in total. Patients were brought to the hospital every four months. Patients were asked to come earlier if they complained of excessive redness, blurred vision, recurrence of the pterygium, or eye pain.

At each follow-up visit, visual acuity, anterior segment examination for intra-ocular complications caused by mitomycin $\mathrm{C}$ application, or Beta Radiation were performed.

Patients signed a written consent form after being adequately explained regarding the study's aim and the possible complications occurring after surgery or any adjuvant therapy used with the operation.

\subsection{Patients were Randomly Divided into Three Groups:}

- Group A had 60 eyes treated for pterygium excision, followed by the application of Beta-radiation.

- Group B comprised 60 eyes treated for pterygium excision and application of $0.02 \%$ mitomycin $\mathrm{C}$ for 5 minutes.

- Group C included 60 eyes treated for pterygium excision and then filling the bare area with conjunctival autograft, harvested from the superior fornix.

\subsection{Pterygium Grading:}

(1) Grade 1: pterygium is midway between the limbus and pupillary margin

(2) Grade 2: pterygium is reaching up to the pupillary margin

(3) Grade 3: completely covering the pupil by pterygium

(4) Grade 4: pterygium extending beyond the pupil.

\subsection{Surgery}

At the start of the operation, the topical application of $0.5 \%$ proxymetacaine hydrochloride (Alcon, USA) was applied to the eye $5 \mathrm{~min}$ before surgery.

Subconjunctival anesthetic (lidocaine 2\% with epinephrine) was injected under the pterygium body. The pterygium head was dissected from the cornea by using a number-15 blade, and part of the pterygium body and Tenon capsule were removed using Westcott scissors. Surgeons attempted a complete excision of the pterygium with a bare sclera.

Patients were then either treated with B-radiation or conjunctival autograft or given $5 \%$ mitomycin $\mathrm{C}$.

\subsection{Beta Radiation}

Following pterygium excision, the tip of a 90 S.R. emitter of the beta radiation device (Nycomed Amersham, U.K.) was placed about $2 \mathrm{~cm}$ above the sclera's bare area for about 15 seconds to ensure that a dose of about 2500 Rads is applied (Fig. 1).

\subsection{Mitomycin C}

After pterygium excision, a sterile sponge of $5 \times 5 \mathrm{~mm}$, soaked with freshly prepared $0.02 \%$ mitomycin C solution, was applied to the bare sclera for 5 minutes. The sponge was then removed, and the area was thoroughly rinsed with a balanced salt solution.

Mitomycin $\mathrm{C}$ was prepared using mitomycin $\mathrm{C}$ powder (Keyowa Hakko Kogyo Co, Tokyo, Japan; 2 mg/vial), which was mixed with $10 \mathrm{ml}$ of tear naturale (Alcon-Couvreur, Puur, Belgium).

\subsection{Conjunctival Autograft}

A Castroviejo caliper was used to measure the amount of conjunctival tissue required to close the exposed scleral defect (Fig. 2a). With the aid of Westcott scissors, the graft was excised, starting at the fornices end. Care was taken to obtain a graft as thin as possible without buttonholing. 


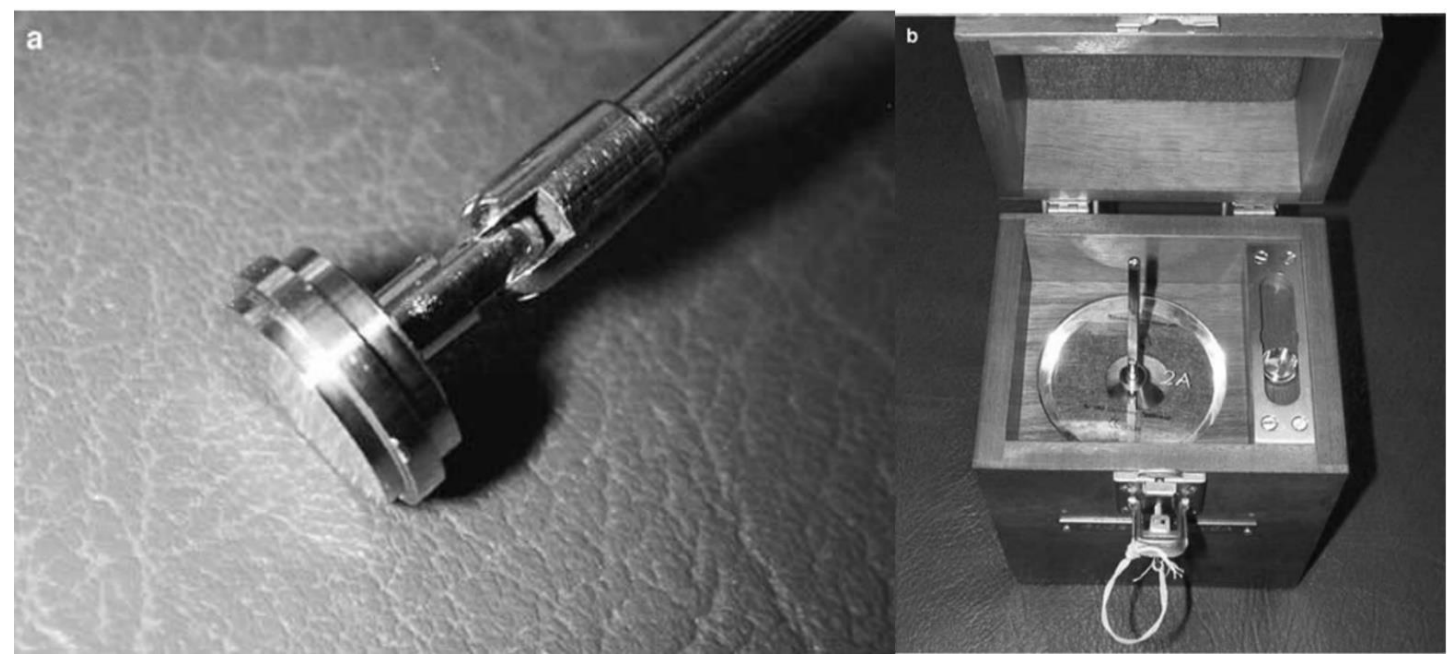

Fig. (1). (a) Tip of 90Sr emitter (Nycomed Amersham, UK). (b) The emitter in a protective case with a lid open to reveal the emitter handle and perspex shield.
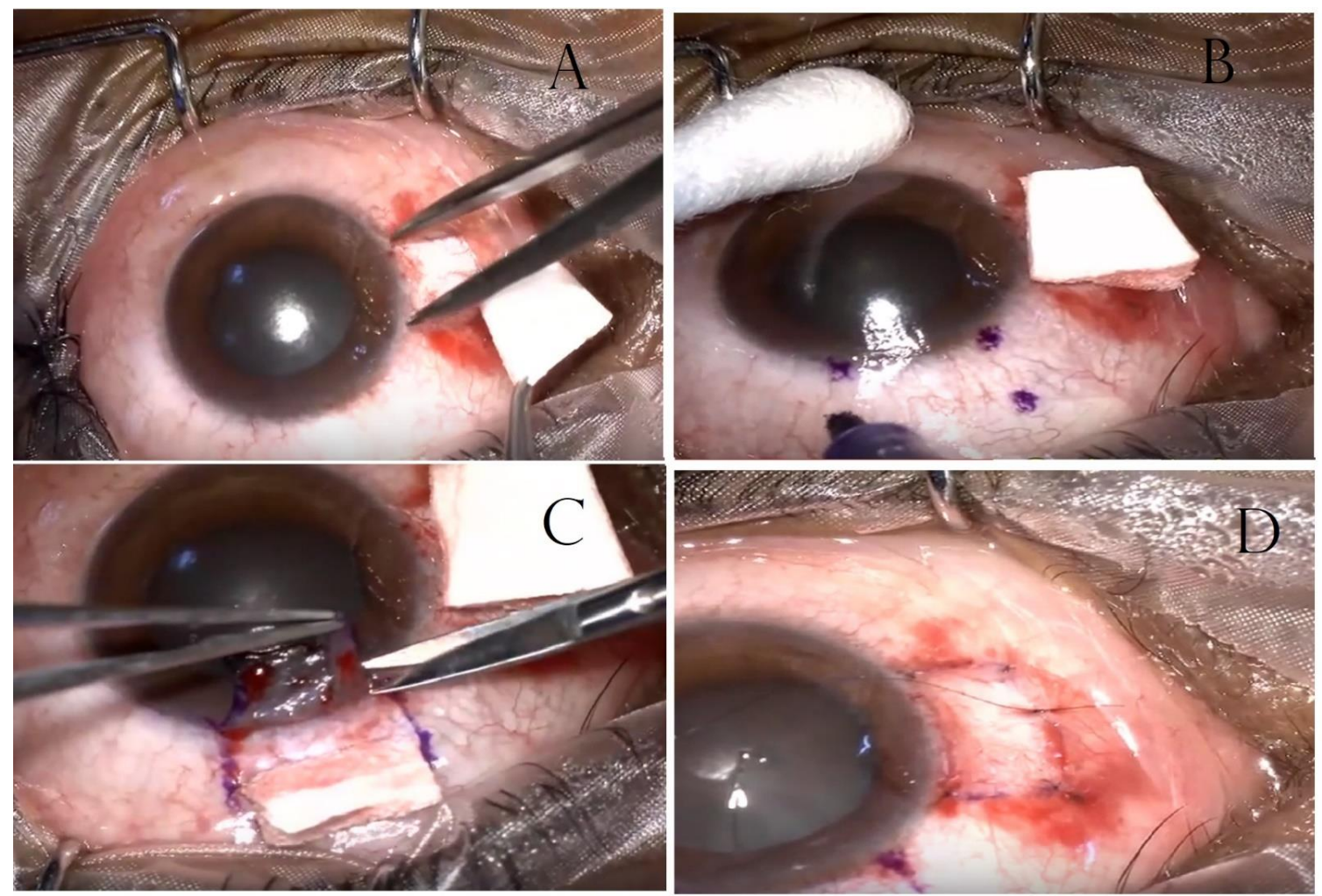

Fig. (2). (a) Measuring the graft size by Castroviejo calipers. (b) Marking the dimensions of the graft on superior-temporal conjunctiva with a gentian violet ink pen. (c) Harvested graft flipped over the cornea and excised using Vannas scissors. (d) 8.0 Vicryl suture used to fix the conjunctiva to the bare sclera sutures that are used for securing the graft in place.

Once the limbus was reached, the graft was flipped over the cornea, and the tenon's attachments at the limbus were meticulously dissected (Fig. 2c). The position of the graft was secured using interrupted 8.0 Vicryl sutures. The four corners of the graft were anchored with episcleral bites to maintain position. No stitches were placed on the limbal side of the graft (Fig. 2d). 
Table 1. Demographic statistics comparing the three groups in the study. Group A patients treated with adjuvant therapy of B-Radiation; Group B patients treated with Mitomycin C after pterygium excision; Group C patients treated with conjunctival graft after the pterygium excision.

\begin{tabular}{|c|c|c|c|c|c|c|c|c|}
\hline & $\begin{array}{l}\text { Number } \\
\text { Of case }\end{array}$ & Sex male gender ${ }^{+}$ & \multicolumn{2}{|c|}{ Age in years } & recurrence & Grade ++ & Scleral melting $^{+}$ & $\begin{array}{l}\text { Superficial } \\
\text { punctate keratitis }^{+}\end{array}$ \\
\hline Group A & 60 & $26.7 \%$ & \multicolumn{2}{|c|}{$47.6 /+/-6.1$} & $33.33 \%$ & $80 \%$ & $6.67 \%$ & $0 \%$ \\
\hline Group B & 60 & $13.33 \%$ & \multicolumn{2}{|c|}{$47.4 /+/-5.9$} & $13.33 \%$ & $80 \%$ & $26.67 \%$ & $26.67 \%$ \\
\hline Group C & 60 & $60 \%$ & \multicolumn{2}{|c|}{$47.4 /+/-4.9$} & $6.67 \%$ & $93.4 \%$ & $0 \%$ & $0 \%$ \\
\hline total & 180 & $33.3 \%$ & \multicolumn{2}{|c|}{$47.4 /+/-5.54$} & $17.78 \%$ & $84.5 \%$ & $11.11 \%$ & $8.89 \%$ \\
\hline & \multicolumn{2}{|l|}{$\begin{array}{l}\text { Post excisional } \\
\text { inflammation }\end{array}$} & corneal opacity & \begin{tabular}{|l|} 
cataract \\
formation
\end{tabular} & \begin{tabular}{l|l} 
& uveitis
\end{tabular} & \multicolumn{2}{|c|}{\begin{tabular}{l|l} 
globe perforation \\
\end{tabular}} & endophthalmitis \\
\hline Group A & $0 \%$ & \multicolumn{2}{|l|}{$0 \%$} & $0 \%$ & $0 \%$ & \multicolumn{2}{|l|}{$0 \%$} & $0 \%$ \\
\hline Group B & $0 \%$ & $0 \%$ & & $0 \%$ & $0 \%$ & $0 \%$ & $0 \%$ & \\
\hline Group C & $0 \%$ & $0 \%$ & & $0 \%$ & $0 \%$ & $0 \%$ & $0 \%$ & \\
\hline total & $0 \%$ & $0 \%$ & & $0 \%$ & $0 \%$ & $0 \%$ & $0 \%$ & \\
\hline
\end{tabular}

Means variables: +the mean percentage of males in the groups. ++ the mean percentage of grade I in comparison to Grade II pterygium. There was no grade 3 pterygium in the study.

\subsection{Postoperative Treatment}

All patients were treated with TobraDex ophthalmic suspension (tobramycin $0.3 \%$, dexamethasone $0.1 \%$; Alcon Laboratories Inc, Fort Worth, Tex) three times/day for two weeks. TobraDex was tapered over a month after the operation.

Tears Guard (Carboxymethylcellulose sodium 0.5\%, manufactured by Orchidia pharmaceutical / Egypt) eye drops were used three times/day for two weeks. Paracetamol 1000mg tablet, three times/day for a week, was prescribed in the case of pain. Finally, any retained sutures were removed in the sixth week.

\subsection{Follow-up Visits}

Patients were followed-up bimonthly in the first couple of months after the operation. Then the visits were extended every three months for three years. A full anterior segment examination using a slit-lamp biomicroscope, intraocular pressure, and visual acuity were performed on each office visit.

Special attention was given to the presence of pterygium, superficial punctuate keratitis, Dellen, scleral melt, globe perforation, uveitis, endophthalmitis, cataract formation, and post excision inflammation.

The researcher defined recurrence as the presence of fibrovascular tissue crossing the corneoscleral limbus. No patients were lost to follow up.

\subsection{Statistical Methods}

Statistical analysis was performed using IBM SPSS Statistics for Windows, Version 25.0 (IBM Corp, Armonk, NY). Descriptive data, including mean, median, mode, and standard deviation of all parameters, are summarized in Table 1. The ANOVA test was used to compare the means of thegrade of the disease, recurrence, scleral melting, post pterygium inflammation, corneal opacity, uveitis, cataract formation, globe perforation, and endophthalmitis.

A P-value of less than 0.05 was considered statistically significant. Both Brown-Forsythe and Welch post-test were applied to the ANOVA test.

\section{RESULTS}

The mean age of the patients was $47.5+/-6.13$ years. The age range was 40 to 61 years old. There was no statistical difference between the means of the age groups among all subtypes $(\mathrm{P}=0.98)$. Around two-thirds $(67 \%)$ of the patients enrolled in the study were males. Of the total number, $51.1 \%$ of patients were farmers, $11.1 \%$ were building workers, and $17.8 \%$ were housewives.

In the study, the ANOVA test showed no statistically significant difference regarding the grade of pterygium among the three groups; P-value was 0.067 . Of these, the total sample constituted mainly grade 1 pterygium, with 148 cases out of $180(82.2 \%)$. The rest were Grade 2 pterygium $(17.8 \%)$. The study sample did not involve grade 3 pterygium or more.

Regarding recurrence, around 20 patients had a highly recurrent pterygium in group A (33.3\%) followed by group B $(13.3 \%)$ and it was least in Group C with a recurrence rate of $6.7 \%$. The ANOVA test showed a significant statistical difference between the three groups (P-value was less than $0.0001)$. Eighty percent of pterygium regrowth occurred in the first three months after the operation; the rest of the recurrent cases occurred in the first year and non-recurred after three years. Table 1 summarizes the demographic statistics and the ANOVA test carried out on the data.

Recurrence was noticed more in male patients. Twentyseven male patients had a recurrence of pterygium; meanwhile, only four female patients had recurrent pterygium. Running the ANOVA test with gender as an independent factor on the three subgroups showed a P-value of 0.006 .

As for scleral melting, group $\mathrm{B}$ had the highest postoperative percentage $(26.6 \%)$, followed by group A $(6.7 \%)$. There were no recorded cases of scleral melting in Group C. The ANOVA test showed a statistically significant difference between the means of scleral melting complication, P (0.0001). 26.7\% of Group B patients had Superficial punctate keratitis. However, Group B and Group C had zero cases.

Females had more incidence of scleral melting than males $(\mathrm{N}=12$ cases). In contrast, males included only eight cases. 
Running the ANOVA test on the three subgroups while gender being the independent factor resulted in a significant P-value of 0.007 .

The other complications surveilled for, such as endophthalmitis, globe perforation, uveitis, corneal opacity, post-excisional inflammation, and cataract, were not recorded in our sample study.

\section{DISCUSSION}

Pterygium surgery has gone through many developmental stages. The first operation was the bare sclera technique; the procedure had a high recurrence $(24 \%-89 \%)$ [4, 11]. The former led to the development of other surgical maneuvers that aimed to lower pterygium recurrence. The adjuvant use of Conjunctival autograft, mitomycin C, 5 F.U, and Beta radiation helped reduce the rate of regrowth of pterygium $[7,12,13]$.

In the current study, we compared three techniques used popularly by ophthalmologists in terms of complication rates. These are conjunctival graft vs. the use of B-radiation vs. the use of mitomycin C. The study's follow-up period was three years. To our knowledge, the current research has the most extended cohort of patients post-pterygium excision.

The first complication was a recurrence of the excised pterygium. This complication was lowest in patients treated with conjunctival Autografting (6.7\%). The ratio was very similar to what has been reported in the literature. Recurrence of pterygium excision with the adjuvant use of conjunctival autograft exhibited a percentage of $1.6 \%-3.3 \%$ to $31.3 \%$ to $33.3 \%$ in some studies $[14,15]$. We believe that the post conjunctival graft was attributed to the presence of a former Dellen, inflamed pterygium, and chronic dryness. It would be beneficial to treat the previous conditions before doing surgery.

On the other hand, we advise giving intense steroid therapy and adequate lubrication to decrease the recurrence rate. Without a doubt, graft survival is crucial for the success of the surgery.

As for B-radiation, our study's recurrence rate was 33.3\%, which was the highest among the groups. M. Ali reported a recurrence rate of $6.82 \%$ following $B$ radiation in patients with pterygium [16]. We believe if excessive cauterization is done at the time of surgery, this will induce the pterygium's aggressive return later on [4].

Besides, we relied on giving a single large dose of radiation at the time of surgery. Some authors suggest that giving 2 or 3 treatments over two months would automatically drop the recurrence rate, as also reported by Smitt M [16].

Finally, the Mitomycin $\mathrm{C}$ group had a recurrence percentage of $13.3 \%$. We used mitomycin C intra-operatively and did not repeat the Mitomycin after surgery. To our knowledge, the current literature suggests that $0,02 \%$ mitomycin $\mathrm{C}$ applied for five minutes is very effective in reducing the recurrence of pterygium [17]. Some papers suggested a recurrence rate of $7 \%$ to $11 \%$ in primary pterygium and $9 \%$ to $15 \%$ in recurrent pterygium [18], which is comparable to our finding. However, newer studies have found that the recurrence rate over a year is around a third of the operated cases. Chen P. reported a recurrence rate of $39 \%$ over a follow-up period of one year and a half, compared to $88 \%$ recurrence in bare scleral excision [12].

Regarding Superficial punctate keratitis, our current study found 16 patients with superficial punctate erosion; all were included in group B $(26.7 \%$, patients treated with adjuvant Mitomycin C). This complication was treated with mild steroids and excessive lubrication. The condition improved in about a month. Superficial punctate keratitis, punctate epitheliopathy, persistent epithelial defects of the cornea and conjunctiva were reported in various studies without mentioning the percentage of patients affected after each procedure [19].

Other complications, like post excision inflammation, corneal opacity, cataract formation, scleral melting, endophthalmitis, and uveitis, were not noticed in any of our patients during the study.

The only limitation of our study was the absence of highgrade pterygium, grade 3 and grade 4 . To our knowledge, no studies have suggested a higher risk of post-surgical complications when operating high-grade pterygium in comparison to low-grade ones. We did not consider risk factors during the study like smoking or high HDL level. Recently, a Chinese study labeled smoking as a protective factor to have pterygium. Meanwhile, early menopause and increased blood level of High-density lipoproteins increase the chance of having grade 2 pterygium or higher. Without a doubt, considering those factors might have given additional information on pterygium postoperative behavior [20].

In conclusion, the adjuvant use of conjunctival autograft after pterygium excision surgery showed the least recurrence rate. The adjuvant use of Mitomycin $\mathrm{C}$ is effective and has a low recurrence rate. However, many authors recommend using mitomycin $\mathrm{C}$ application in conjunction with conjunctival flaps or graft, rather than being used alone [13, 21].

\section{CONCLUSION}

In conclusion, the adjuvant use of conjunctival autograft after pterygium excision surgery showed the least recurrence rate. The adjuvant use of Mitomycin $\mathrm{C}$ is effective and has a low recurrence rate. However, many authors recommend using mitomycin $\mathrm{C}$ application in conjunction with conjunctival flaps or graft, rather than being used alone [13, 21].

\section{ETHICS APPROVAL AND CONSENT TO PARTI- CIPATE}

This study was approved by the Institutional Review Board and Research Ethics Committee of Fayoum University, Egypt under approval no. (2139/10/2016).

\section{HUMAN AND ANIMAL RIGHTS}

No Animals were used in this research. All human research procedures followed were in accordance with the ethical standards of the committee responsible for human experimentation (institutional and national), and with the Helsinki Declaration of 1975, as revised in 2013. 


\section{CONSENT FOR PUBLICATION}

Not applicable.

\section{STANDARDS OF REPORTING}

CONSORT guidelines have been followed.

\section{FUNDING}

None.

\section{CONFLICT OF INTEREST}

The authors declare no conflict of interest, financial or otherwise.

\section{ACKNOWLEDGEMENTS}

Declared none.

\section{REFERENCES}

[1] Daponte PL, Cigna A, Lescano O, et al. Conjunctival autograft with fibrin glue for pterygium: A long term recurrence assessment. Med Hypothesis Discov Innov Ophthalmol 2019; 8(4): 272-7. [PMID: 31788488]

[2] Huang X, Zhu B, Lin L, Jin X. Clinical results for combination of fibrin glue and nasal margin suture fixation for attaching conjunctival autografts after pterygium excision in Chinese pterygium patients. Med (United States) 2018; 97(44)

[http://dx.doi.org/10.1097/MD.0000000000013050]

[3] He S, Sun H, Huang Y, et al. Identification and interaction analysis of significant genes and micrornas in pterygium. Biomed Res Int 2019 [http://dx.doi.org/10.1155/2019/2767512]

[4] Lešin M, Paradžik M, Marin Lovrić J, et al. Cauterisation versus fibrin glue for conjunctival autografting in primary pterygium surgery (CAGE CUP): Study protocol of a randomised controlled trial BMJ Open 2018; 8(6): e020714.

[http://dx.doi.org/10.1136/bmjopen-2017-020714] [PMID: 29950464]

[5] Bayar SA, Kucukerdonmez C, Oner O, Akova YA. Subconjunctival bevacizumab in the impending recurrent pterygia. Int Ophthalmol 2014; 34(3): 541-7.

[http://dx.doi.org/10.1007/s10792-013-9852-1] [PMID: 24026871]

[6] Özülken K, Koç M, Ayar O, Hasiripi H. Topical cyclosporine A administration after pterygium surgery. Eur J Ophthalmol 2012; 22(Suppl. 7): S5-S10

[http://dx.doi.org/10.5301/ejo.5000004] [PMID: 21725937]

[7] Meneghim RLFS, Satto LH, Natsuaki KL, et al. Topical cyclosporine A $0.05 \%$ before and after surgery to prevent pterygium recurrence. Arq Bras Oftalmol 2019; 82(5): 372-6. [PMID: 31271569]

[8] Kim DJ, Lee JK, Chuck RS, Park CY. Low recurrence rate of anchored conjunctival rotation flap technique in pterygium surgery.
BMC Ophthalmol 2017; 17(1): 187.

[http://dx.doi.org/10.1186/s12886-017-0587-z] [PMID: 29017515]

[9] Hwang HS, Cho KJ, Rand G, Chuck RS, Kwon JW. Optimal size of pterygium excision for limbal conjunctival autograft using fibrin glue in primary pterygia. BMC Ophthalmol 2018; 18(1): 135.

[http://dx.doi.org/10.1186/s12886-018-0790-6] [PMID: 29879926]

[10] Phathanthurarux S, Chantaren P. A survey of surgical techniques in Pterygium, Thailand 2016. Asia Pac J Ophthalmol (Phila) 2019; 8(6): 476-80.

[http://dx.doi.org/10.1097/01.APO.0000605100.25659.f7] [PMID: 31789650]

[11] Clearfield E, Hawkins BS, Kuo IC. Conjunctival autograft versus amniotic membrane transplantation for treatment of pterygium: Findings from a cochrane systematic review. Am J Ophthalmol 2017; 182: 8-17.

[http://dx.doi.org/10.1016/j.ajo.2017.07.004] [PMID: 28734814]

[12] Ghoz N, Elalfy M, Said D, Dua H. Healing of autologous conjunctival grafts in pterygium surgery. Acta Ophthalmol 2018; 96(8): e979-88. [http://dx.doi.org/10.1111/aos.13794] [PMID: 30156059]

[13] Martins TG dos S, Costa AL, Alves MR, Chammas R, Schor P. Mitomycin C in pterygium treatment. Int J Ophthalmol 2016; 9(3): 465-8.

[PMID: 27158622]

[14] Fernandes M, Sangwan VS, Bansal AK, et al. Outcome of pterygium surgery: Analysis over 14 years. Eye (Lond) 2005; 19(11): 1182-90. [http://dx.doi.org/10.1038/sj.eye.6701728] [PMID: 15543190]

[15] Nuzzi R, Tridico F. How to minimize pterygium recurrence rates: Clinical perspectives. Clin Ophthalmol 2018; 12: 2347-62. [http://dx.doi.org/10.2147/OPTH.S186543] [PMID: 30538417]

[16] Viani GA, De Fendi LI, Fonseca EC, Stefano EJ. Low or high fractionation dose $\beta$-radiotherapy for pterygium? A randomized clinical trial. Int J Radiat Oncol Biol Phys 2012; 82(2): e181-5. [http://dx.doi.org/10.1016/j.ijrobp.2010.11.017] [PMID: 21596485]

[17] Ari S, Çaca I, Yildiz ZÖ, Şakalar YB, Dogan E. Comparison of mitomycin $\mathrm{C}$ and limbal-conjunctival autograft in the prevention of pterygial recurrence in Turkish patients: A one-year, randomized, assessor-masked, controlled trial. Curr Ther Res Clin Exp 2009; 70(4): 274-81.

[http://dx.doi.org/10.1016/j.curtheres.2009.08.004] [PMID: 24683237]

[18] Hayasaka S, Noda S, Yamamoto Y, Setogawa T. Postoperative instillation of low-dose mitomycin $\mathrm{C}$ in the treatment of primary pterygium. Am J Ophthalmol 1988; 106(6): 715-8

[http://dx.doi.org/10.1016/0002-9394(88)90706-4] [PMID: 3143266]

[19] Panda A, Das GK, Tuli SW, Kumar A. Randomized trial of intraoperative mitomycin $\mathrm{C}$ in surgery for pterygium. Am J Ophthalmol 1998; 125(1): 59-63.

[http://dx.doi.org/10.1016/S0002-9394(99)80235-9] [PMID: 9437314]

[20] Pan Z, Cui J, Shan G, et al. Prevalence and risk factors for pterygium: A cross-sectional study in Han and Manchu ethnic populations in Hebei, China. BMJ Open 2019; 9(2)e025725

[http://dx.doi.org/10.1136/bmjopen-2018-025725] [PMID: 30796128]

[21] Frucht-Pery J, Raiskup F, Ilsar M, Landau D, Orucov F, Solomon A. Conjunctival autografting combined with low-dose mitomycin $\mathrm{C}$ for prevention of primary pterygium recurrence. Am J Ophthalmol 2006; 141(6): 1044-50.

[http://dx.doi.org/10.1016/j.ajo.2005.12.028] [PMID: 16546105]

\section{(C) 2020 Al-Salem et al}

This is an open access article distributed under the terms of the Creative Commons Attribution 4.0 International Public License (CC-BY 4.0), a copy of which is available at: (https://creativecommons.org/licenses/by/4.0/legalcode). This license permits unrestricted use, distribution, and reproduction in any medium, provided the original author and source are credited. 